\title{
Association of shared decision making with inpatient satisfaction: a cross-sectional study
}

\author{
Huiwen Luo', Guohua Liu², Jing Lu² and Di Xue ${ }^{1 *}$ (D)
}

\begin{abstract}
Background: We assessed inpatient perceived shared decision making (SDM) and tested the association of SDM with inpatient satisfaction in public tertiary hospitals in Shanghai, China.

Methods: A cross-sectional survey of 2585 inpatients in 47 public tertiary hospitals in Shanghai in July and August 2018 was conducted. We assessed overall SDM and 4 aspects of SDM and tested the factors influencing SDM and the association of SDM with patient satisfaction (patient satisfaction with physician services, medical expenses, outcomes and overall inpatient care), by adopting linear or two-level regression models.

Results: The positive response rate (PRR) and high positive response rate (HPRR) to overall SDM among the inpatients of public tertiary hospitals in Shanghai were relatively high ( $95.30 \%$ and $87.86 \%$, respectively), while the HPRR to "My physician informed me of different treatment alternatives" was relatively low (80.09\%). In addition, the inpatients who underwent surgery during admission had higher HPRRs and adjusted HPRRs to overall SDM than those who did not undergo surgery. The study showed that the adjusted high satisfaction rates (HSRs) with physician services, medical expenses, outcomes and overall inpatient care among the inpatients with high level of overall SDM were higher $(96.50 \%, 68.44 \%, 89.50 \%$ and $92.60 \%)$ than those among the inpatients without a high level of overall SDM $(71.77 \%$, $35.19 \%, 57.30 \%$ and $67.49 \%)$. The greatest differences in the adjusted HSRs between the inpatients with and without a high level of SDM were found in inpatient satisfaction with medical expenses and informed consent in SDM. Moreover, $46.22 \%$ of the variances in the HSRs with overall inpatient care across the hospitals were attributed to the hospital type (general hospitals vs. specialty hospitals).
\end{abstract}

Conclusions: Inpatient PRRs and HPRRs to SDM in public tertiary hospitals in Shanghai are relatively high overall but lower to information regarding alternatives. SDM can be affected by the SDM preference of both the patients and physicians and medical condition. Patient satisfaction can be improved through better SDM and should be committed at the hospital level.

Keywords: Shared decision making, Patient satisfaction, Medical care quality, Tertiary hospitals

*Correspondence: xuedi@shmu.edu.cn

1 Department of Hospital Management, School of Public Health, NHC Key Laboratory of Health Technology Assessment, Fudan University, No. 138,

Yi Xue Yuan Road, Shanghai 200032, People's Republic of China

Full list of author information is available at the end of the article

\section{Background}

Shared decision making (SDM) involves the participation of both physicians and patients in medical decision making by weighing the available medical evidence and the values and preferences of patients $[1,2]$. The aim of SDM is to promote patient autonomy and make informed, patient-centered decisions [3, 4]. SDM consists 
of the following four elements: two parties (physicians and patients) involved in SDM, participation during the process of decision making by both physicians and patients, information sharing as a prerequisite for SDM, and a treatment decision made and agreed upon by the physician and patient [5]. The core of SDM is that physicians and patients develop the best treatment plan for the patients through discussion with the aim to maximize patients' benefits $[6,7]$.

To measure SDM, the API [8], the Perceived Involvement in Care Scale (PICS) [9], the 9-item Shared Decision Making Questionnaire (SDM-Q-9) [10], the Shared Decision Making Questionnaire-physician version (SDM-QDoc) [11], and CollaboRATE [12] are often used to assess patients' information preference, patient involvement in SDM and encouragement from physicians to achieve SDM. However, informed consent, which reflects respect for patient autonomy in special medical care (such as high-risk, costly or considerable out-of-pocket medical care), is not included in current SDM studies. In an era during which new technology is developed very rapidly, informed consent should not be neglected when some new technologies introduce higher risks and financial burden to patients.

In studies of SDM, patient characteristics (e.g., age, education level, and gender) and suitable treatment situations for SDM (e.g., disease characteristics, therapeutic options and availability of scientific evidence regarding the treatment efficacy) are considered potential factors that may affect SDM by some researchers $[13,14]$. Additionally, socioeconomic factors may influence patients' perceptions of SDM [15].

Patient satisfaction is a key measure of the quality of healthcare systems that reflects patients' experiences and has been added to the performance assessments of hospitals in some countries [16, 17]. Many researchers have studied on the effect of SDM on patient satisfaction, treatment satisfaction, decision satisfaction and trust, timeliness of diagnosis and decisions, necessity of referrals, diagnostic tests and medical treatment, patient adherence to medications and treatment, patient safety, health outcomes, and patient rights and welfare [18-26]. Some studies reported positive results, while some studies indicated that a negative or no relationship exists between SDM and health outcomes [27]. Because physician services represent a basic concern in medical care, medical expenses still impose a great financial challenge to patients, and patients are the least satisfied with medical expenses [28]. Treatment outcomes affect patients' health and quality of life; thus, determining whether a high level of SDM specifically leads to better patient perceptions of physician services, medical expenses and treatment outcomes is warranted.

\section{Objectives}

The goals of this study were to analyze the status of SDM and the influencing factors of SDM in inpatient care in tertiary public hospitals in Shanghai, and determine whether SDM leads to higher inpatient satisfaction with overall inpatient care, physician services, medical expenses and treatment outcomes.

\section{Methods}

\section{Data source}

A cross-sectional inpatient survey was conducted in 47 tertiary public hospitals (32 general hospitals and 15 specialty hospitals) in Shanghai in July and August 2018. Only three tertiary public hospitals in Shanghai (one mental health center, one hospital specializing in infectious disease, and one hospital with no inpatient care) were excluded from the study. Because $90 \%$ of all patients receive medical care at public hospitals in China [29], patient care in public hospitals can generally represent patient care in China.

A random sample of inpatients who had completed their main medical care (e.g., surgeries or therapeutic procedures) was selected from each of the sampled tertiary public hospitals within one workweek. The average number of sampled inpatients per hospital was 55 (5279). All voluntary investigators, who were mainly senior medical students from major medical colleges in Shanghai, received training regarding the inpatient survey. The survey was conducted via an e-questionnaire administered using iPads. Oral informed consent was obtained before the patients' participation in the survey.

In the questionnaire survey, data related to inpatient satisfaction, inpatients' perceived SDM, public hospital type (general vs. specialty), inpatient characteristics [e.g., gender, age, residence (Shanghai vs. non-Shanghai), education, family monthly income ( $<5 \mathrm{k}, 5 \mathrm{k}-, 10 \mathrm{k}-, 20 \mathrm{k-}$, or $50 \mathrm{k}$ yuans)], patients with or without cancer (yes vs. no), having surgery (yes vs. no) and admitting clinical department (e.g., internal medicine, surgery, gynecology, pediatrics, other) were collected.

\section{Measures \\ SDM scale}

Four aspects were used to assess SDM in inpatient care, including "Patients' information preference", "Patients' active involvement in SDM", "Patients' perceived encouragement from their physicians to achieve SDM" and "Informed consent". Of the four aspects, the former two aspects reflected the patients' desire for autonomy, while the latter two aspects reflected the patients' perceived autonomy support [20]. The items in the aspects of "Patients' information preference", "Patients' active involvement in SDM", and "Patients' perceived 
encouragement from their physicians to achieve SDM" were based on the API [8], PICS [9], and the SDM-Q-9, SDM-Q-Doc, CollaboRATE and PICS [9-12], respectively. The items in the aspect of "Informed consent" were developed by the authors. Twenty-five experts in medical care quality from Shanghai were consulted regarding all items on the SDM scale. During the consultation, each item related to SDM was rated according to its importance by experts, and a 10-point scale was adopted for the rating ( 1 for "very unimportant" and 10 for "very important"). If the average score of the importance of an item was equal to or greater than 7 , the item was included in the SDM assessment (Additional file 1: Table S1). Finally, 13 items were used in this study to assess the four aspects of SDM in inpatient care (Table 1).

Each item in the SDM assessment was rated using a 5-point Likert scale as follows: 1 for "strongly disagree", 2 for "disagree", 3 for "neither agree nor disagree", 4 for "agree" and 5 for "strongly agree". The SDM measure used in this study had relatively acceptable construct validity and internal reliability (goodness of fit using a confirmatory factor analysis model: $\mathrm{SRMR}=0.09, \mathrm{RMSEA}=0.12$, $\mathrm{GFI}=0.86, \mathrm{AGFI}=0.79$; and overall Cronbach's $\alpha=0.82$ ).

In this study, the percentage of inpatients who rated an item on the SDM scale as "strongly agree" or "agree" was referred to as the positive response rate (PRR) to this item, and the percentage of inpatients who rated an item on the SDM scale as "strongly agree" was referred to as high positive response rate (HPRR) to this item.

\section{Inpatient satisfaction scale}

Based on our previous inpatient satisfaction scale and consultation with experts in medical care quality, four dimensions with 35 items were used to assess inpatient satisfaction (Additional file 1: Table S2). The four dimensions of the inpatient satisfaction scale were "Facilities and equipment", "Physician services", "Nonphysician services" and "Medical care process and effectiveness". To assess the association of inpatients' perceived SDM with their satisfaction, overall inpatient satisfaction with medical care, the dimension of "Physician services" (hereafter "physician services") and two items ["Medical expenses are reasonable" and "I was satisfied with medical care outcomes" (hereafter "medical expenses" and "treatment outcomes", respectively)] were used.

Each item on the inpatient satisfaction scale was scored using a 5-point Likert scale as follows: 1 for "very dissatisfied", 2 for "dissatisfied", 3 for "neither satisfied nor dissatisfied", 4 for "satisfied" and 5 for "very satisfied". If an item was irrelevant to a surveyed inpatient, the item was treated as a missing value for this patient. In the analyses, a missing value of an item was replaced by the average score of the item. The percentage of inpatients who rated medical care equal to 5 is referred to as the inpatient high satisfaction rate (HSR).

Table 1 PRRs and HPRRs to SDM among inpatients in tertiary hospitals in Shanghai

\begin{tabular}{lll}
\hline Aspects and items & PRR (\%) & HPRRs (\%) \\
\hline Patients' information preference & $\mathbf{9 7 . 3 3}$ \\
I should sufficiently understand the effects of the disease(s) that I have on my health & 96.43 & $\mathbf{9 0 . 0 4}$ \\
The physician should explain to me the purposes of the test(s) and/or examination(s) & 98.07 & 88.33 \\
I believe that getting information about the disease(s) is as important as getting information about the treat- & 97.48 & 90.95 \\
ment & $\mathbf{9 3 . 7 1}$ \\
Patients' active involvement in SDM & 91.78 \\
I asked my physician to explain the treatment alternatives and process in detail & 91.10 \\
I asked my physician to provide treatment recommendations to me & 98.26 \\
I described my disease symptoms to my physician in detail & $\mathbf{9 4 . 8 8}$ \\
Patients' perceived encouragement from their physicians to achieve SDM & 97.95 \\
My physician provided me with detailed information about the disease(s) that I have & 98.24 \\
My physician explained to me the diagnostic and therapeutic decisions that I need to make & 88.63 \\
My physician informed me of different treatment alternatives & 91.50 \\
My physician asked me which treatment alternative I prefer & 98.10 \\
My physician and I reached a consensus on the subsequent treatment process & $\mathbf{9 5 . 6 9}$ \\
Informed consent & 93.78 \\
My physician explained the medical expenses of special medical care & 93.92 \\
My physician obtained informed consent from me for special medical care & $\mathbf{8 2 . 2 9}$ \\
Overall & $\mathbf{9 5 . 3 0}$ & $\mathbf{8 7 . 2 1}$ \\
\hline
\end{tabular}

PRRs, positive response rates; HPRRs, high positive response rates; $\mathrm{n}=2585$ 
The psychometric analysis indicated that the inpatient satisfaction measure used in this study had relatively good construct validity based on standard tests of goodness of fit using a confirmatory factor analysis model (GFI $=0.85$; $\mathrm{AGFI}=0.90 ; \mathrm{SRMR}=0.04$; and $\mathrm{RMSEA}=0.05)$ and had high internal reliability (overall Cronbach's $\alpha=0.95$ ).

\section{Statistical analyses}

We computed the average PRR and HPRR of the items related to a given aspect as the PRR and HPRR of each aspect of SDM, respectively. We also calculated the average PRR and HPRR if the 13 items on the SDM scale in the survey as a summary statistic, which we refer to as "overall PRR" and "overall HPRR", respectively. Overall HPRR was computed as the average of all responses received and then computed separately for general hospitals and specialty hospitals, inpatients with cancer and inpatients without cancer, and inpatients who underwent surgery and inpatients who did not undergo surgery.

We computed the HSRs of overall medical care, physician services, medical expenses and treatment outcomes. The HSRs of physician services and overall inpatient care were the average HSRs of the items related to the "Physician services" dimensions and all items on the inpatient satisfaction scale.

To examine whether the hospital type, admission department, inpatient with cancer, and surgery during admission affected the inpatients' HPRRs to the four aspects of SDM and overall SDM, we applied t-tests and linear regression models.
To illustrate the differences in the adjusted HPRRs between groups of inpatients, we used the coefficients in linear regression models to calculate the adjusted HPRRs while holding all other variables constant at their means and graphically present the relevant predictions.

To test the differences in the inpatients' overall HSRs and HSRs of physician services, medical expenses and treatment outcomes between the inpatients with or without high level of overall SDM and the four aspects of SDM, we used two-level regression models that accounted for the nesting of individuals within hospitals. In the models, high level of SDM referred to the average HPRRs of each aspect of SDM or overall SDM that were equal to or greater than $80 \%$, while a non-high level of SDM referred to the average HPRRs of each aspect of SDM or overall SDM that were less than $80 \%$. More specifically, two-level linear regression models were used to analyze overall HSR and the HSR of physician services, and the dependent variables were the average HSRs of the items in the "Physician services" dimension and all items on the inpatient satisfaction scale; two-level logistic models were used for the HSRs of medical expenses and treatment outcomes (1: "very satisfied", 0: others). In addition, high-level SDM, the inpatients' characteristics (admitting department, inpatient with cancer, surgery during admission, gender, age, residence, education and family monthly income) and the hospital type were used as fixed effects.

The following equations were applied in the two-level mixed linear regression models:

$$
\begin{aligned}
\text { HSR }_{i j}=\beta_{0 j} & +\beta_{1} \text { high-level_of_SDM } \\
& +\beta_{4} \text { Pediatrics }_{i j}+\beta_{5} \text { Surgery }_{i j}+\beta_{3} \text { Obstetrics and gynecology }_{i j} \\
& +\beta_{8} \text { Gender }_{i j}+\beta_{9} \text { Age }_{i j}+\beta_{10} \text { Residence }_{i j}+\beta_{11} \text { Education }_{i j}+\beta_{12} \text { Income }_{i j}+e_{0 j}
\end{aligned}
$$

$$
\beta_{0 j}=\gamma_{00}+\gamma_{01} \text { hospital_type }{ }_{1 j}+\mu_{0 j}
$$

$$
\begin{aligned}
\operatorname{HSR}_{i j}=\gamma_{00} & +\gamma_{01} \text { hospital_type }_{1 j}+\beta_{1} \text { high-level_of_SDM } \\
i j & +\beta_{2} \text { Surgery }_{i j}+\beta_{3} \text { Obstetrics and gynecology }_{i j} \\
& +\beta_{4} \text { Pediatrics }_{i j}+\beta_{5} \text { Other_departments }_{i j}+\beta_{6} \text { Cancer }_{i j}+\beta_{7} \text { Surgery }_{i j}+\beta_{8} \text { Gender }_{i j} \\
& +\beta_{9} \text { Age }_{i j}+\beta_{10} \text { Residence }_{i j}+\beta_{11} \text { Education }_{i j}+\beta_{12} \text { Income }_{i j}+\left(\mu_{0 j}+e_{0 j}\right)
\end{aligned}
$$

The following equations were applied in the two-level logistic regression models:

$$
\begin{aligned}
\text { In }\left[\mathrm{p}_{i j} /\left(1-\mathrm{p}_{i j}\right)\right]=\beta_{0 j} & +\beta_{1} \text { high-level_of_SDM }_{i j}+\beta_{2} \text { Surgery }_{i j}+\beta_{3} \text { Obstetrics and gynecology }_{i j} \\
& +\beta_{4} \text { Pediatrics }_{i j}+\beta_{5} \text { Other_departments } \\
i j & +\beta_{6} \text { Cancer }_{i j}+\beta_{7} \text { Surgery }_{i j} \\
& +\beta_{8} \text { Gender }_{i j}+\beta_{9} \text { Age }_{i j}+\beta_{10} \text { Residence }_{i j}+\beta_{11} \text { Education }_{i j}+\beta_{12} \text { Income }_{i j}
\end{aligned}
$$




$$
\begin{gathered}
\beta_{0 j}=\gamma_{00}+\gamma_{01} \text { hospital_type }_{1 j}+\mu_{0 j} \\
\begin{aligned}
\text { In }\left[\mathrm{p}_{i j} /\left(1-\mathrm{p}_{i j}\right)\right]= & \gamma_{00} \\
+ & \gamma_{01} \text { hospital_type }_{1 j}+\beta_{1} \text { high-level_of_SDM }_{i j}+\beta_{2} \text { Surgery }_{i j} \\
& +\beta_{3} \text { Obstetrics and gynecology }_{i j}+\beta_{4} \text { Pediatrics }_{i j}+\beta_{5} \text { Other_departments }_{i j} \\
& +\beta_{6} \text { Cancer }_{i j}+\beta_{7} \text { Surgery }_{i j}+\beta_{8} \text { Gender }_{i j}+\beta_{9} \text { Age }_{i j}+\beta_{10} \text { Residence }_{i j} \\
& +\beta_{11} \text { Education }_{i j}+\beta_{12} \text { Income }_{i j}+\mu_{0 j}
\end{aligned}
\end{gathered}
$$
HSRs of overall inpatient care across hospitals and indi-

In the above equations, $i=1,2, \ldots, n, j=1,2, \ldots, m ; n$ is the number of surveyed inpatients, and $m$ is the number of surveyed hospitals.

To determine the appropriateness of the two-level regression models, we examined the empty models of the inpatients' overall HSR and HSRs to physician services, medical expenses and treatment outcomes. The results showed significant differences in HSRs among hospitals $(P<0.001)$, and the intraclass correlation coefficients (ICC) in the empty models of the inpatients' overall HSR and HSRs to physician services, medical expenses and treatment outcomes were 0.12, 0.08, 0.09 and 0.09, respectively. Additionally, the -2 log likelihood, AIC, AICC and BIC in the empty models of the inpatients' overall HSR and HSRs to physician services and treatment outcomes were greater than those in the non-empty models, and those in the empty model of the inpatients' HSR to medical expenses were close to those in the nonempty model in this study. Therefore, two-level regression models were appropriate for the analysis of the association between SDM and inpatient satisfaction. viduals, using the method described by Snijders and Bosker.

This study was approved by the Institutional Review Board of the School of Public Health, Fudan University (IRB\#2018-05-0683).

\section{Results}

\section{Inpatient characteristics}

In total, 2585 inpatients in tertiary public hospitals (hereafter "tertiary hospitals") in Shanghai participated in the study. Among the surveyed inpatients, $69.90 \%$ were from general hospitals, $55.86 \%$ were aged below 60 years, $52.19 \%$ were female, $73.15 \%$ had a high school education or below, $37.18 \%$ had a family monthly income below 5 thousand yuans, and $60.85 \%$ were Shanghai residents. In addition, $15.05 \%$ of the surveyed inpatients suffered from

\begin{tabular}{|c|c|c|c|c|c|}
\hline Variables & $\begin{array}{l}\text { Patients' information } \\
\text { preference }\end{array}$ & $\begin{array}{l}\text { Patients' active } \\
\text { involvement in SDM }\end{array}$ & $\begin{array}{l}\text { Patients' perceived encouragement } \\
\text { from their physicians to achieve SDM }\end{array}$ & $\begin{array}{l}\text { Informed } \\
\text { consent }\end{array}$ & Overall \\
\hline \multicolumn{6}{|c|}{ General hospital } \\
\hline Yes & 89.87 & 85.04 & 87.54 & 89.75 & 87.84 \\
\hline No & 90.43 & 86.80 & 86.45 & 89.51 & 87.92 \\
\hline \multicolumn{6}{|c|}{ Pediatric department } \\
\hline Yes & 88.47 & 88.25 & 86.70 & 88.85 & 87.80 \\
\hline No & 90.07 & 85.51 & 87.22 & 89.70 & 87.87 \\
\hline \multicolumn{6}{|c|}{ Suffering from cancer } \\
\hline Yes & 90.93 & 86.24 & $90.01^{*}$ & 91.46 & 89.57 \\
\hline No & 89.88 & 85.45 & 86.71 & 89.36 & 87.56 \\
\hline \multicolumn{6}{|c|}{ Surgery during admission } \\
\hline Yes & $91.49^{*}$ & 86.66 & $88.96^{* * *}$ & 90.38 & $89.23^{* *}$ \\
\hline No & 88.90 & 84.71 & 85.83 & 89.13 & 86.79 \\
\hline
\end{tabular}
cancer, and $44.06 \%$ of the inpatients had at least one surgery during hospitalization. The inpatients admitted to internal medicine, surgery, obstetrics and gynecology, pediatrics and other departments accounted for $34.31 \%$,

Table 2 Comparison of HPRRs to SDM between different groups of inpatients (\%)

HPRRs, high positive response rates; SDM, shared decision making

${ }^{*} P<0.05 ;{ }^{* *} P<0.01 ;{ }^{* * *} P<0.001$ 


\section{a}

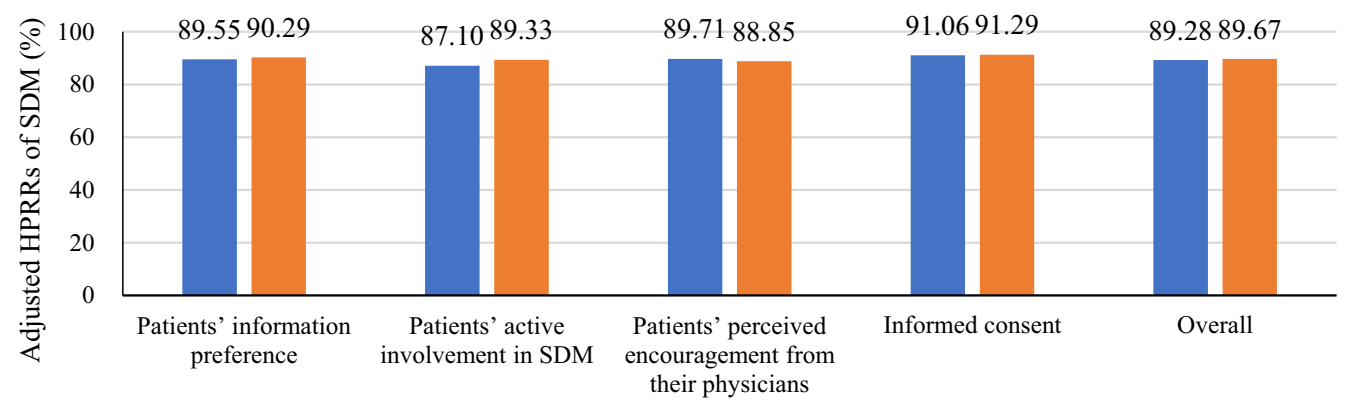

b $\quad$ General hospitals $\quad$ Special hopsitals

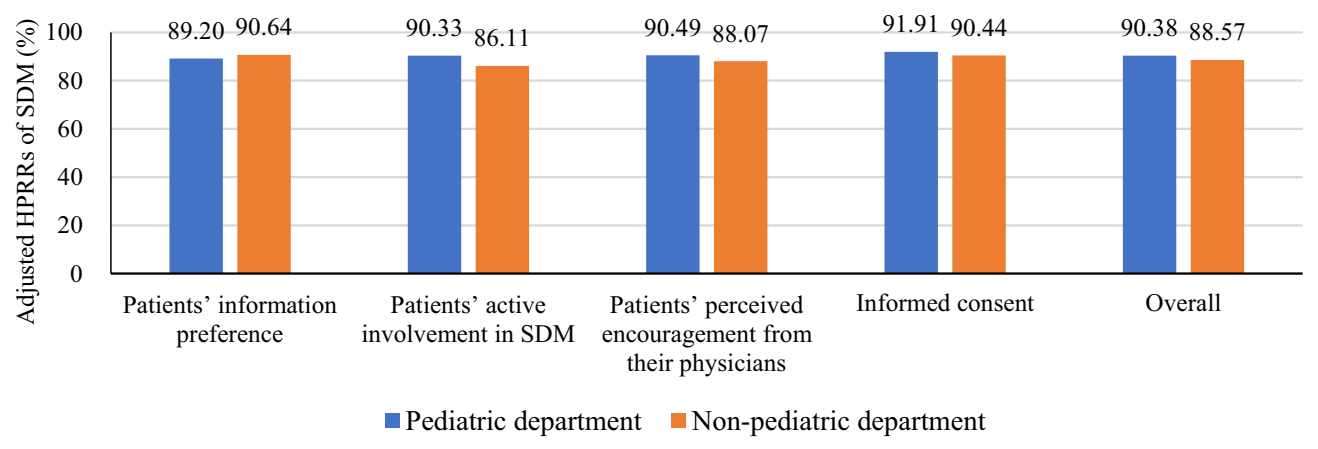

c

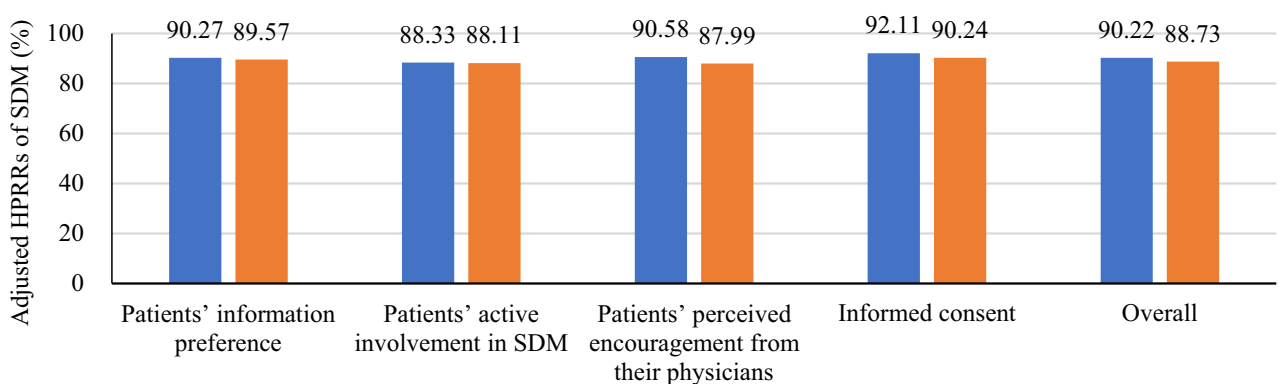

-With Cancer $\quad$ Without cancer

d

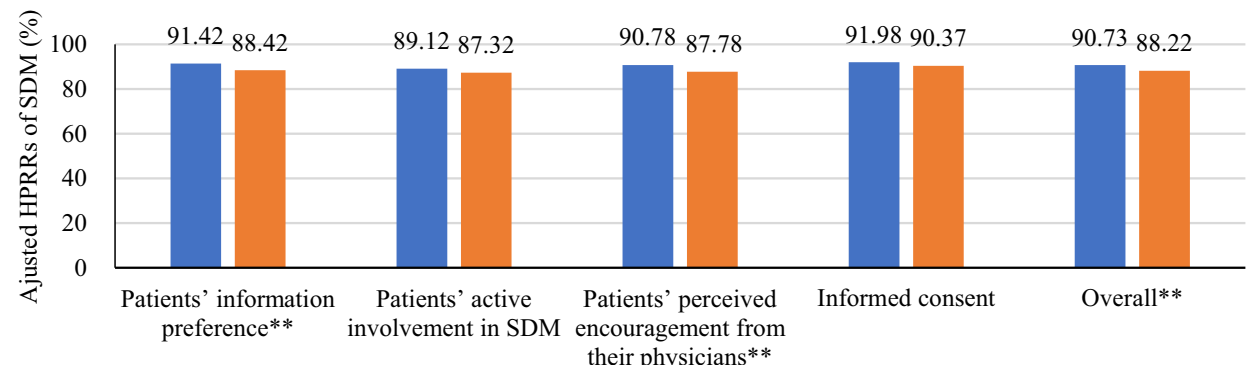

- Having any surgery $\square$ Having no any surgery

$$
* * \mathrm{P}<0.01 \text {. }
$$

Fig. 1 Comparison of the adjusted PRRs to SDM between different groups of inpatients. ${ }^{*} P<0.01$ 
Table 3 Comparison of adjusted HSRs between inpatients with or without a high level of SDM (\%)

\begin{tabular}{|c|c|c|c|c|}
\hline Variables $^{\mathbf{a}}$ & Overall & Physician services & Medical expenses & $\begin{array}{l}\text { Treatment } \\
\text { outcomes }\end{array}$ \\
\hline \multicolumn{5}{|c|}{ Patients' information preference } \\
\hline High level of SDM & 91.53 & 95.35 & 66.87 & 88.56 \\
\hline Non-high level of SDM & 70.09 & 74.80 & 39.34 & 58.81 \\
\hline \multicolumn{5}{|c|}{ Patients' active involvement in SDM } \\
\hline High level of SDM & 91.84 & 95.74 & 67.36 & 88.39 \\
\hline Non-high level of SDM & 72.62 & 76.89 & 42.27 & 64.37 \\
\hline \multicolumn{5}{|c|}{$\begin{array}{l}\text { Patients' perceived encouragement from their physi- } \\
\text { cians to achieve SDM }\end{array}$} \\
\hline High level of SDM & 92.33 & 96.23 & 67.30 & 88.81 \\
\hline Non-high level of SDM & 67.33 & 71.57 & 38.03 & 58.28 \\
\hline \multicolumn{5}{|l|}{ Informed consent } \\
\hline High level of SDM & 90.38 & 94.20 & 65.65 & 86.24 \\
\hline Non-high level of SDM & 64.79 & 70.00 & 30.44 & 57.16 \\
\hline \multicolumn{5}{|l|}{ Overall SDM } \\
\hline High level of SDM & 92.60 & 96.50 & 68.44 & 89.50 \\
\hline Non-high level of SDM & 67.49 & 71.77 & 35.19 & 57.30 \\
\hline
\end{tabular}

Two-level mixed linear regression models were used to analyze the overall HSR and HSR with physician services, and the dependent variables were the average HSRs of all items on the inpatient satisfaction scale and the items in the "Physician services" dimension; Two-level logistic models were used to analyze the HSRs with medical expenses and treatment outcomes (1: "very satisfied", 0: others); two-level regression models were used to calculate the adjusted HSRs of the inpatients with or without positive responses to SDM while controlling for the hospital type, admitting department, inpatient characteristics (age, sex, residence, education and income), inpatient with or without cancer, and having surgery; all p-values of the t-tests in the models were $<0.0001$; SDM, shared decision making; HSRs, high positive response rates

a The group of inpatients with a high level of SDM was defined as the inpatient group in which all inpatients had an average HPRR to an aspect or overall equal to or greater than $80 \%$, while the group of inpatients with a non-high level of SDM was referred as the inpatient group in which inpatients had an average HPRR to an aspect or overall less than $80 \%$

$33.73 \%, 13.11 \%, 2.21 \%$, and $16.64 \%$ of the sample, respectively (Additional file 1: Table S3).

\section{Inpatient PRRs and HPRRs to SDM}

This study showed that the PRR and the HPPR to overall SDM among the inpatients in the tertiary hospitals in Shanghai were $95.30 \%$ and $87.86 \%$, respectively. The HPRRs of the four aspects of SDM ("Patients' information preference", "Patients' active involvement in SDM", "Patients' perceived encouragement from their physicians to achieve SDM" and "Informed consent") were $90.04 \%$, $85.57 \%, 87.21 \%$ and $89.68 \%$, respectively. Although all items related to the four aspects had HPRRs above $80 \%$ (80.09-91.54\%), "My physician informed me of different treatment alternatives" had the lowest HPRR (80.09\%) (Table 1).

\section{Comparison of HPRRs between different groups \\ of inpatients}

This study showed that the inpatients who underwent any surgery during admission had higher HPRRs to "Patients' information preference", "Patients' perceived encouragement from their physicians to achieve SDM" and overall SDM than those who did not undergo surgery during admission (91.49\%, 88.96\% and $89.23 \%$ vs.
$88.90 \%, 85.83 \%$ and $86.79 \%$, respectively). The inpatients with cancer had a higher HPRR to "Patients' perceived encouragement from their physicians to achieve SDM" than those without cancer $(90.01 \%$ vs. $86.71 \%$ ) (Table 2 ).

After the application of the linear regression models (Additional file 1: Table S4), the inpatients who underwent surgery had a relatively higher adjusted HPRR to "Patients' information preference" (91.42\%), "Patients' perceived encouragement from their physicians to achieve SDM" (90.78\%) and overall SDM (90.73\%) than those who did not undergo surgery $(88.42 \%, 87.78 \%$ and $88.22 \%$, respectively). However, there was no significant difference in the adjusted HPRR of overall SDM and the four aspects between the inpatients with or without cancer, between the inpatients in general hospitals or specialty hospitals or between the inpatients in pediatric or non-pediatric departments (Fig. 1).

\section{Association of SDM with inpatient satisfaction}

Among the surveyed inpatients, the HSRs of overall inpatient care, physician services, medical expenses, and treatment outcomes were $87.63 \%, 91.45 \%, 61.70 \%$ and $83.06 \%$, respectively.

After the adoption of the two-level regression models to account for the nesting of individuals within hospitals 
and control for other fixed effects, the study showed that the inpatients with a high level of overall SDM had higher adjusted HSRs with overall inpatient care, physician services, medical expenses and treatment outcomes $(92.60 \%$, $96.50 \%, 68.44 \%$ and $89.50 \%$, respectively) than those without a high level of overall SDM $(67.49 \%, 71.77 \%$, $35.19 \%$ and $57.30 \%$, respectively) (Table 3 ).

Regarding to inpatient satisfaction with overall inpatient care, physician services, medical expenses and treatment outcomes, the greatest differences in the adjusted HSRs between the inpatients with or without a high level of all four aspects of SDM were found in the "Medical expenses" item (25-36 percentage points). Among the 4 aspects of SDM, the greatest differences in the adjusted HSRs were observed in the "Informed consent" aspect (24-36 percentage points) (Table 3 and Additional file 1: Table S5-S9).

\section{Variation in inpatient satisfaction across hospitals}

The two-level regression models of the HSRs showed that the inpatient HSRs with overall inpatient care, physician services and treatment outcomes in the specialty hospitals were significantly lower than those in the general hospitals after controlling for a high level of overall SDM and other individual factors (Additional file 1: Table S5). When analyzing the variances using the method described by Snijders and Bosker, the results showed that $46.22 \%$ of the variances in the HSRs with overall inpatient care across the hospitals were attributed to the hospital type (general hospitals vs. specialty hospitals), while $30.80 \%$ of the variances in the HSRs with overall inpatient care across individuals were attributed to the Level-1 model.

\section{Discussion}

\section{Relatively high overall SDM but lower informing regarding alternatives}

In recent years, due to rapid innovation and more uncertainty in medical care, hospitals have become increasingly aware of the need to deliver "patient-centered" care and have paid increasing attention to physician-patient communication and SDM [30, 31]. In this study, we found that the PRR and the HPPR of overall SDM among the inpatients in tertiary hospitals in Shanghai were $95.30 \%$ and $87.86 \%$, respectively. The HPRRs to 'Patients' active involvement in SDM" and "Patients' perceived encouragement from their physicians to achieve SDM" among the inpatients in tertiary hospitals in Shanghai were $85.57 \%$ and $87.21 \%$, respectively, which are close to those reported in other studies [87\% of patients with newly diagnosed, localized prostate cancer who reported being actively involved in treatment decision making [32] and the mean SDM-Q-9 score $(68$, full score $=100)$ and median CollaboRATE score $(93$, full score $=100)$ of outpatients with vascular malformations [33]]. In recent years, the action plan called for by the central and local governments to further improve medical service and train staff in physician-patient communication skills [34, 35] has facilitated the implementation of SDM in tertiary hospitals in Shanghai.

However, similar to another study in cardiology that revealed that fewer patients reported "some" or "a lot of" discussions regarding the advantages and disadvanges of treatment options ( $88 \%$ and $58 \%$ regarding transcatheter aortic valve replacement and $78 \%$ and $49 \%$ regarding surgical aortic valve replacement, respectively) [36], we found that the HPRR to "My physician informed me of different treatment alternatives" was relatively low (80.09\%). The basis for patients' involvement in treatment decisions is patients' full understanding of different treatment alternatives [37], which is also the basis for patients signing informed consent for surgery. If patients are not informed about alternatives, it is difficult for them to know whether the treatment recommended by their physicians will be the most beneficial.

\section{SDM affected by preference and medical condition}

In this study, we found that inpatients who underwent any surgery during admission had better perceptions of SDM than those who did not undergo any surgery. These findings persisted when we used linear regression models to control for other factors. Complex clinical decisions with higher risks and more critical health outcomes in the patients' survey [38] may have led to both patients and physicians having a higher preference for SDM. Moreover, informed consent before surgery is required not only as a legal doctrine but also as patient-centered care [39]. SDM in inpatients undergoing surgery helps physicians understand patients' values, preferences, and needs and helps patients understand the benefits and risks of surgical alternatives to reduce physician-patient conflict and protect patient interests [40, 41]. These factors may explain the better SDM in the inpatients who underwent any surgery.

Similar to other studies [42, 43], our study found that inpatients with cancer had a significantly higher HPRR to "Patients' perceived encouragement from their physicians to achieve SDM" than those without cancer $(90.01 \%$ vs. $86.71 \%$ ). The reason for this finding could be that the guidelines for communication with cancer patients strongly recommend that physicians clarify the treatment goals to support their patients' hope and understanding, provide information regarding all available treatment options and the advantages and disadvantages of each option, and respect the patients' treatment autonomy [44]. However, there was no significant difference in the 
adjusted HPRRs in SDM between the inpatients with or without cancer.

\section{Inpatient satisfaction improved by SDM}

Our study revealed that the inpatients with a high level of responses regarding overall SDM had much higher adjusted HSRs with physician services, medical expenses, treatment outcomes and overall inpatient care $(96.50 \%$, $68.44 \%, 89.50 \%$ and $92.60 \%$, respectively) than those without a high level of overall responses $(71.77 \%, 35.19 \%$, $57.30 \%$ and $67.49 \%$, respectively).

Furthermore, our study revealed the unique finding that SDM had a greater influence on inpatient satisfaction with medical expenses and that informed consent had a greater influence on inpatient satisfaction with tertiary hospitals in Shanghai. In tertiary hospitals, medical expenses can be a high burden for patients, and treatment selection is an important determinant of patient outcomes. A higher level of SDM can reduce medical costs of care $[4,45]$, facilitate discussion regarding the benefits, risks and costs (including considerable outof-pocket treatments) of options [36, 46] and enhance informed consent for complex clinical decisions [47]. Therefore, better SDM (especially informed consent) in tertiary hospitals in Shanghai can improve patient satisfaction with medical expenses, treatment outcomes, physician services and overall patient satisfaction.

\section{Increase in patient satisfaction at the hospital level}

Patients' experience with medical care is an important aspect of the quality of care. The measurement of patients' experiences and the dissemination of measurement results can help identify weaknesses in medical care, improve the medical care quality and promote patient choice $[48,49]$. In total, $46.22 \%$ of the variances in the HSRs with overall inpatient care across the hospitals were attributed to the hospital type (general hospitals vs. specialty hospitals), and the inpatients in the specialty hospitals had lower satisfaction with overall medical care than those in the general hospitals, highlighting the importance of hospital-level commitment to increasing patient satisfaction. To facilitate improvement in patient satisfaction in tertiary hospitals, especially specialty hospitals, patients' experiences or satisfaction and SDM should be measured, the results should be disseminated, and incentives should be provided for delivering "patientcentered" care.

\section{Limitations}

All hospitals included in our study were located in Shanghai, which is among the most developed areas in China, and our findings may not be generalizable to hospitals in other areas of China. In addition, the inpatients surveyed in our study had not been discharged from the hospitals, although they had completed their main medical care (e.g., surgeries or therapeutic procedures). Therefore, systemic bias may exist in the patient selection. However, the overall satisfaction rate of the inpatients who were still hospitalized did not significantly differ from that of inpatients who were surveyed during their hospital discharge process $(96.71 \%$ vs. $97.01 \%, P>0.05)$ in our contemporaneous survey. The inpatients surveyed during their hospital discharge process were not surveyed with regard to SDM. Therefore, the bias from our inpatient survey might not be significant. Moreover, many factors contribute to patients' perceived SDM and patient satisfaction [50-52]. We used linear regression models and two-level regression models to minimize some potential confounders (e.g., socioeconomic factors), but other confounders were not considered in this study. In addition, the SDM measure used in this study did not have high construct validity. All above limitations may affect our results to some extent.

\section{Conclusions}

The inpatient PRRs and HPRRs to SDM in public tertiary hospitals in Shanghai are relatively high overall but lower to information regarding alternatives. Furthermore, SDM can be affected by the SDM preferences of both patients and physicians and the medical condition. Patient satisfaction with physician services, medical expenses, treatment outcomes and overall inpatient care can be improved through better SDM, especially by providing information regarding treatment alternatives to patients and obtaining informed consent when treatments or procedures are high risk, expensive or involve considerable out-of-pocket costs, and hospital-level commitment.

\section{Supplementary information}

The online version contains supplementary material available at https://doi. org/10.1186/s12911-021-01385-1.

Additional file 1. Supplementary tables.

\section{Abbreviations}

SDM: Shared decision making; PICS: Perceived Involvement in Care Scale; SDM-Q-9: 9-Item Shared Decision Making Questionnaire; SDM-Q-Doc: Shared Decision Making Questionnaire-physician version; PRR: Positive response rate; HPRR: High positive response rate; SR: Satisfaction rate; HSR: High satisfaction rate.

\section{Acknowledgements}

We gratefully acknowledge the significant contributions of Shuwen Chen, Xia $\mathrm{Xu}$ and the research volunteers in conducting the questionnaire surveys and/ or sharing their views with us during the research process. The authors also acknowledge all hospitals and the Shanghai Health Commission for providing assistance with the research project. 


\section{Authors' contributions}

$X D, L G$ and LH were involved in the design of the study; $L J$ and LH collected the data; LH and XD analyzed the data and wrote the manuscript; and XD and $L G$ revised the manuscript. All authors read and approved the final manuscript.

\section{Funding}

This research was funded by the Shanghai Medical Ethos Association.

\section{Availability of data and materials}

The dataset used in the current study is available from the corresponding author upon reasonable request.

\section{Ethics approval and consent to participate}

This study was approved by the Institutional Review Board (IRB) of the School of Public Health, Fudan University (IRB\#2018-05-0683). Oral informed consent was approved by the IRB and obtained before the patients' participation in the survey.

\section{Consent for publication}

Not applicable.

\section{Competing interests}

The funding body of the study, the Shanghai Medical Ethos Association, participated in the design of the study and collection and interpretation of data, and involved in writing the manuscript. The authors declare that have no competing interests.

\section{Author details}

${ }^{1}$ Department of Hospital Management, School of Public Health, NHC Key Laboratory of Health Technology Assessment, Fudan University, No. 138, Yi Xue Yuan Road, Shanghai 200032, People's Republic of China. ${ }^{2}$ Shanghai Medical Ethos Association, Jiangan District, No. 328, Huashan Road, Shanghai 200040, People's Republic of China.

\section{Received: 22 June 2020 Accepted: 6 January 2021}

Published online: 25 January 2021

\section{References}

1. Huang R, Gionfriddo MR, Zhang L, Leppin AL, Ting HH, Montori VM. Shared decision-making in the People's Republic of China: current status and future directions. Patient Prefer Adherence. 2015;9:1129-41.

2. Levine DM, Landon BE, Linder JA. Trends in patient-perceived shared decision making among adults in the United States, 2002-2014. Ann Fam Med. 2017;15(6):552-6.

3. Barry MJ, Edgman-Levitan S. Shared decision making-pinnacle of patientcentered care. N Engl J Med. 2012;366(9):780-1.

4. Oshima Lee E, Emanuel EJ. Shared decision making to improve care and reduce costs. N Engl J Med. 2013;368(1):6-8.

5. Charles C, Gafni A, Whelan T. Shared decision-making in the medical encounter: what does it mean? (or it takes at least two to tango). Soc Sci Med. 1997;44(5):681-92.

6. Hulme K, Chilcot J, Smith MA. Doctor-patient relationship and quality of life in Irritable Bowel Syndrome: an exploratory study of the potential mediating role of illness perceptions and acceptance. Psychol Health Med. 2018;23(6):674-84.

7. Grünloh C, Myreteg G, Cajander $\AA$, Rexhepi H. "Why do they need to check me?" Patient participation through eHealth and the doctor-patient relationship: qualitative study. J Med Internet Res. 2018;20(1):e11.

8. Ende J, Kazis L, Ash A, Moskowitz MA. Measuring patients' desire for autonomy: decision making and information-seeking preferences among medical patients. J Gen Intern Med. 1989:4(1):23-30.

9. Lerman CE, Brody DS, Caputo GC, Smith DG, Lazaro CG, Wolfson HG. Patients' perceived involvement in care scale: relationship to attitudes about illness and medical care. J Gen Intern Med. 1990;5(1):29-33.

10. Baicus C, Balanescu P, Gurghean A, Badea CG, Padureanu V, Rezus C, Mitu F, Jurcut R, Balanescu AR, Daha I, et al. Romanian version of SDM-Q-9 validation in internal medicine and cardiology setting: a multicentric cross-sectional study. Rom J Intern Med. 2019;57(2):195-200.
11. Scholl I, Kriston L, Dirmaier J, Buchholz A, Harter M. Development and psychometric properties of the Shared Decision Making Questionnairephysician version (SDM-Q-Doc). Patient Educ Couns. 2012;88(2):284-90.

12. Rosenberg D, Schön UK, Nyholm M, Grim K, Svedberg P. Shared decision making in Swedish community mental health services: an evaluation of three self-reporting instruments. J Ment Health (Abingdon, Engl). 2017;26(2):142-9.

13. Arora NK, McHorney CA. Patient preferences for medical decision making: who really wants to participate? Med Care. 2020;38(3):335-41.

14. Müller-Engelmann M, Keller H, Donner-Banzhoff N, Krones T. Shared decision making in medicine: the influence of situational treatment factors. Patient Educ Couns. 2020;82(2):240-7.

15. Attanasio LB, Kozhimannil KB, Kjerulff KH. Factors influencing women's perceptions of shared decision making during labor and delivery: results from a large-scale cohort study of first childbirth. Patient Educ Couns. 2018;101(6):1130-6.

16. Dottino JA, He W, Sun CC, Zhao H, Fu S, Lu KH, Meyer LA. Centers for Medicare and Medicaid Services' Hospital Consumer Assessment of Healthcare Providers and Systems (HCAHPS) scores and gynecologic oncology surgical outcomes. Gynecol Oncol. 2019;154(2):405-10.

17. General Office of the State Council, China. Opinions of the general office of the state council on strengthening the performance appraisal of tertiary public hospitals. http://www.gov.cn/zhengce/content/2019-01/30/ content 5362266.htm?trs=1.

18. Street RL Jr, Makoul G, Arora NK, Epstein RM. How does communication heal? Pathways linking clinician-patient communication to health outcomes. Patient Educ Couns. 2009;74(3):295-301.

19. Saheb KM, McGill ET, Berger ZD. Shared decision-making and outcomes in type 2 diabetes: a systematic review and meta-analysis. Patient Educ Couns. 2017;100(12):2159-71.

20. Lee YY, Lin JL. Do patient autonomy preferences matter? Linking patientcentered care to patient-physician relationships and health outcomes. Soc Sci Med. 2010;71(10):1811-8.

21. Shay LA, Lafata JE. Where is the evidence? A systematic review of shared decision making and patient outcomes. Med Decis Making. 2015:35(1):114-31.

22. Mahlich J, Matsuoka K, Sruamsiri R. Shared decision making and treatment satisfaction in Japanese patients with inflammatory bowel disease. Dig Dis. 2017;35(5):454-62.

23. Kashaf MS, McGill E. Does shared decision making in cancer treatment improve quality of life? A systematic literature review. Med Decis Making. 2015:35(8):1037-48.

24. Altin SV, Stock S. The impact of health literacy, patient-centered communication and shared decision-making on patients' satisfaction with care received in German primary care practices. BMC Health Serv Res. 2016:16:450.

25. Mahlich J, Schaede U, Sruamsiri R. Shared decision-making and patient satisfaction in Japanese rheumatoid arthritis patients: a new "preference fit" framework for treatment assessment. Rheumatol Ther. 2019;6(2):269-83

26. Sepucha KR, Atlas SJ, Chang Y, Freiberg A, Malchau H, Mangla M, Rubash $H$, Simmons LH, Cha T. Informed, patient-centered decisions associated with better health outcomes in orthopedics: prospective cohort study. Med Decis Making. 2018;38(8):1018-26.

27. Légaré F, Tremblay S, O'Connor AM, Graham ID, Wells GA, Jacobsen MJ. Factors associated with the difference in score between women's and doctors' decisional conflict about hormone therapy: a multilevel regression analysis. Health Expect. 2003;6(3):208-21.

28. Liu J, Mao Y. Patient satisfaction with rural medical services: a crosssectional survey in 11 western provinces in China. Int J Environ Res Public Health. 2019;16(20):3968.

29. National Health Commission. China health statistics yearbook. Beijing: Peking Union Medical College Press; 2018.

30. Huang $R$, Song $X$, Wu J, Huang W, Leppin AL, Gionfriddo MR, Liu Y, Boehmer KR, Ting HH, Montori VM. Assessing the feasibility and quality of shared decision making in China: evaluating a clinical encounter intervention for Chinese patients. Patient Prefer Adherence. 2016;10:2341-50.

31. Lu C, Li X, Yang K. Trends in shared decision-making studies from 2009 to 2018: a bibliometric analysis. Front Public Health. 2019;7:384.

32. van Stam MA, Pieterse AH, van der Poel HG, Bosch J, Tillier C, Horenblas S, Aaronson NK. Shared decision making in prostate cancer 
care-encouraging every patient to be actively involved in decision making or ensuring the patient preferred level of involvement? J Urol. 2018;200(3):582-9.

33. Horbach SE, Ubbink DT, Stubenrouch FE, Koelemay MJ, van der Vleuten CJ, Verhoeven BH, Reekers JA, Schultze Kool LJ, van der Horst CM. Shared decision-making in the management of congenital vascular malformations. Plast Reconstr Surg. 2017;139(3):725e-34e.

34. General Office of National Health Commission. A notice on the issuance of assessment indicators of the action plan for further improvement of medical services (2018-2020). http://www.nhc.gov.cn/yzygj/s3594 q/201810/1 ba10172ba8c4a719f812997ec4209ff.shtml.

35. Shanghai Municipal Health Commission. Notice on the issuance of the implementation plan of Shanghai municipality's action plan for further improving medical services (2018-2020). http://wsjkw.sh.gov.cn/yzgl3 /20180831/62195.html.

36. Rao B, Dickert NW, Morris AA, Speight C, Smith G, Shore S, Moore M. Abstract 21: heart failure and shared decision-making: patients' perspectives regarding medication-related cost discussions. Circ Cardiovasc Qual Outcomes. 2020;13:A21. https://doi.org/10.1161/hcq.13.suppl_1.21.

37. Zhang Y, Su H, Shang L, Li D, Wang R, Zhang R, Xu Y. Preferences and perceived involvement in treatment decision making among Chinese patients with chronic hepatitis. Med Decis Making. 2011;31(2):245-53.

38. de Mik SML, Stubenrouch FE, Balm R, Ubbink DT. Systematic review of shared decision-making in surgery. Br J Surg. 2018;105(13):1721-30.

39. Chima SC. Evaluating the quality of informed consent and contemporary clinical practices by medical doctors in South Africa: an empirical study. BMC Med Ethics. 2013;14(Suppl 1):S3.

40. Shinkunas LA, Klipowicz CJ, Carlisle EM. Shared decision making in surgery: a scoping review of patient and surgeon preferences. BMC Med Inform Decis Making. 2020;20(1):190.

41. Shaw S, Hughes G, Stephens T, Pearse R, Prowle J, Ashcroft RE, Avagliano E, Day J, Edsell M, Edwards J, et al. Understanding decision making about major surgery: protocol for a qualitative study of shared decision making by high-risk patients and their clinical teams. BMJ Open. 2020;10(5):e033703

42. Tamirisa NP, Goodwin JS, Kandalam A, Linder SK, Weller S, Turrubiate S, Silva C, Riall TS. Patient and physician views of shared decision making in cancer. Health Expect. 2017;20(6):1248-53.

43. Han J, Jungsuwadee P, Abraham O, Ko D. Shared decision-making and women's adherence to breast and cervical cancer screenings. Int J Environ Res Public Health. 2018;15(7):1509.
44. Gilligan T, Bohlke K, Baile WF. Patient-clinician communication: American Society of Clinical Oncology consensus guideline summary. J Oncol Pract. 2018:14(1):42-6.

45. Veroff D, Marr A, Wennberg DE. Enhanced support for shared decision making reduced costs of care for patients with preference-sensitive conditions. Health Aff (Millwood). 2013;32(2):285-93.

46. Dennison Himmelfarb CR, Koirala B, Coke LA. Shared decision making: partnering with patients to improve cardiovascular care and outcomes. J Cardiovasc Nurs. 2018;33(4):301-3.

47. James JT, Eakins DJ, Scully RR. Informed consent, shared-decision making and a reasonable patient's wishes based on a cross-sectional, national survey in the USA using a hypothetical scenario. BMJ Open. 2019;9(7):e028957.

48. Black N, Jenkinson C. Measuring patients' experiences and outcomes. BMJ. 2009. https://doi.org/10.1136/bmj.b2495.

49. Wong WS, Fielding R. The association between patient satisfaction and quality of life in Chinese lung and liver cancer patients. Med Care. 2008:46(3):293-302

50. Attanasio $L B$, Kozhimannil KB, Kjerulff KH. Factors influencing women's perceptions of shared decision making during labor and delivery: results from a large-scale cohort study of first childbirth. Patient Edu Couns. 2018;6(101):1130-6.

51. Boudreaux ED, Ary RD, Mandry CV, McCabe B. Determinants of patient satisfaction in a large, municipal ED: the role of demographic variables, visit characteristics, and patient perceptions. Am J Emerg Med. 2000;18(4):394-400.

52. Paredes AZ, Idrees JJ, Beal EW, Chen Q, Cerier E, Okunrintemi V, Olsen G, Sun S, Cloyd JM, Pawlik TM. Influence of English proficiency on patient-provider communication and shared decision-making. Surgery. 2018;163(6):1220-5

\section{Publisher's Note}

Springer Nature remains neutral with regard to jurisdictional claims in published maps and institutional affiliations.
Ready to submit your research? Choose BMC and benefit from:

- fast, convenient online submission

- thorough peer review by experienced researchers in your field

- rapid publication on acceptance

- support for research data, including large and complex data types

- gold Open Access which fosters wider collaboration and increased citations

- maximum visibility for your research: over $100 \mathrm{M}$ website views per year

At BMC, research is always in progress.

Learn more biomedcentral.com/submissions 